exceptional opportunities I am convinced that nothing but the compulsory periodical examination of prostitutes, and their compulsory detention in hospital until cured, will bave any material effect in diminishing the prevalence of venereal disease among the population; while to the women them. selves the advantage of early surgical treatment is incalculable. Voluntary Lock $H$ spitials on an adequate scale will never be supported hy the public, and if they were they would be of little us. These women are far too reckless of consequences to apply for admission, and to seclude them. selves for treatment until their disease has reached a stage which renders it impossible for them to pursue their calling any longer, and until they have already done all the misshief of which they are capable. The treatment of them as out-patients, which is done on so large a scale at present, is a positive injury to the public health, by enabling them to practise prostitution with less pain to themselves, and for a longer period than it would otherwise be possible for them to do.

\section{CASE OF DOUBLE POPLITEAL ANEURISM. CURED IN TWENTY-ONE HOURS.}

BT ALEXANDER PATTERSON, M.D.,

GERGBON TO, AND LECTURER OX CLINTCAL SUBGEBY AT, THE WHSTYRY INFIRYARY, GLASGOW.

CASES of external aneurism are of frequent occurrence, and are always replete with interest to the surgeon. Until the introduction of the stethoscope many cases of internal anenrism must have escaped the observation of the physician; while, for ages back, sight and touch have rendered surgeons familiar with the disease as it appears in the limbs.

Compression and ligature, applied in different methods and in varying positions, are the principal modes of surgical treatment. Pressure, as usually tried by the older surgeons, was effected by placing pads over the tumour and along the track of the artery, and then bandaging the limb firmly, with the intention of keeping the sac empty and of causing adhesion of its walls, At the same time the patient was confined to bed, kept on low diet, and had blood repeatedly drawn from his arm, during the progress of the case. We can scarcely be surprised that, with such practice, the failures far out-numbered the cures.

The ancient plan of deligation consisted in laying open the sac, clearing it of its contents, and tying the vessel above and below. Pott, referring to this mode of treatment, says: "Sorry I am to find myself obliged to say that, as far as my observation and experience go, such operation, how. ever judiciously performed, will not be succsseful-that is, will not save the patient's life. In hoth these aneurismsthe femoral and pnpliteal-it most frequently happens that the artery is not only dilated and burst, but it is also distempered some way above the dilatation, particularly in the popliteal. 'This may very probably be one reason why the igature is in general so unsuccessful." He then proceeds to say that amputation of the thigh onght to be preferred to the incision of the popliteal aneurismal sac.

Anel first tied the artery external to the sac without opening it. He performed the operation only once, and that, as is well known, in a case of traumatic aneurism at the bend of the elbow, and where in all probability he had sound arterial coats to deal with. Whilst a warding to Anel full credit for the genius which led him to devise, and the skill which enabled him to execute successfully, his unprecedented operation, let it not be confounded with the Hunterian operation. Anel's method, if tried on an ordi. nary non-traumatic aneurism, would almost certainly fail, because of the diseased arterial coats, and death would take place from secondarv hæmorrbage.

In December, 1785 , Jubn Hunter performed his first operation at St. Groorge's Hospital. Everard Home, in describing the first five operations, states that four liga. tnres were employed in the first, that vein and artery were both ineluded, and that the ligatures were not drawn tightly, only "to comprese the sides of the ressels, and take off the force of the circulation." 'The patient recovered. In the second case one ligature on'y was used, vein and artery included. The patient died of secondary bæmorrbage on the twenty-sixth day. In the third case one ligature only was used; vein and artery tied ; ligature care away on the fourteenth day; wound perfectly healed in four weeks. In the fourth case the artery alone deligated; ligature came away on the twenty-ninth day; wound healed in seven weeks. In the fifth case one ligature only was used on artery; dropped off on the eleventh day; well in five weeks. In one of the foregoing cases $\mathrm{Mr}$. Hunter tried instrumental compression by means of an instrument somewhat like a bernial truss, but, the patient being unable to bear it, it was abandoned.

Instrumental compression was brought to the notice of the profession chiefly by the surgeons of Dublin, where the first case was cured in 1842 . The principle upon which they applied this treatment was in imitation of the natural mode of cure, considering it necessary only to lessen the force of the blood-current through the sac, thus affording opportunity for lamin ted cagula to form in the tumour. The average time required by this treatment is about twonty days. Wbat is termed the " $r$ tpid cure of aneurism by pressure," first practised by the Newcaktle surgeons, differs in principle from the preceding, in so far that the patient is placed under the influence of chloroform, and the circulation at once and completely arrested, allowing the blood to coagulate in the tumour, pressure being applied both above and below the tumnur. One or two cases are recorded of cures effected in the wonderfully short period of twenty minutes. The first case cur $d$ hy digital compression alone was that under the care of Dr Knight, of Newhaven, U S , in 1848, in which he succeed d after forty hours of continuous pressure. The average duration of the compression necessary appears to be about forty-one and a balf bours, spread over a variable portivn of time, owing to the intermissions in the process.

R. W- aged twenty-six, was admitted to the Western Intirmary on the 10th of January, 1877. The patient is a fair complexioned, healthy-looking man, of low stature, filling the position of in pector of eloth in a weaving factory, where he stands all day at his duty. Patient states that three years and a half ago he suffered from what he calls a pretty smart attack of rheumatism-not so severe, however, as to preclude him from following his employment. When his stomach was disordered be was annoyed by palpitation. He was unaccustomed to active exercise, but in the beginning of May last he played for about hall an hour at cricket, when he received $a$ blow on the front of the left ankle-joint, which, be says, has since been the cause of much trouble. The foot became swollen and painful, yet not to such an extent as to throw him ciff work. Ten weeks ago, when the ankle had ceased giving him annopance, he felt, whilst at work, a stiffness in the left knee-juint, and experienced slight pain on stooping. On ex,mining the knee at night, he detected a small soft swelling in the left popliteal space, in which he felt a slight pulsation. To this be gave little attention, attributing it to a kiud of rheumatic pain excited by the injured ankle. Atout a fortnight afterwards, on casually examining the right ham, he discovered a swelling similar to that in the left, but slightly smaller, in which also he detected pulsation on pressure with the finger. Shortly after this time be complained of a feeling of numbness in the right foot, which in a week or two became considerably swollen, and bad a hot, uncomfortable sensation. During this pericd $b$,th $s$ wellings had rapidly increased in size, and the pulsation was becoming more and more marked, accompanied by pain as if a red-hrt cinder were present in each popliteal space. The swelling in the right foot after some time extended upwards towards the knee, causing a heavy, dragging pain as if a weight were at tached to the limb. During all this time the left ankle gave him no trouble, and the pain in the left limb was inconsiderable compared with that in the right.

On examination, a well-marked aneurism was found to exist in each popliteal space; that in the right was about the size of a goose egg, and easily emptied of its contents; the left was not quite go large, and gave one the idea that the sac walls were of greater density. All the usual signs of a nenrism were present in botb tumonrs. A double murmur was andible in the right, and a single sound conld be beard in the left; heart found to be pretty. nornal, if anything a 
elight enlargement of cardiac area, and a little irregularity of beat existed; no evidence of aortic aneurism detected; general health good.

Treatment.-On the 12th of January (two days after admission) the left leg was firmly flexed, and kept so by bandaging. On the $13 \mathrm{th}$, digital pressure was commenced at 11 A.M., by compressing the right femoral artery in Scarpa's space, and kept up without intermission until 11 P.M., when pulsation was found to have entirely ceased, and the tumour to be much lessened in size. On Jan. 15th, at the visit hour, the swelling was not much larger than a pigeon's egg, being now hard and solid. At 2 p.M. digital compression was applied to the left femoral, and kept up continuously until 11 P.M.- that is to say, for nine hours. At the visit hour next morning (the 16th) pulsation was gone, the tumour solid, and much diminished in size.

No great pain was experienced during the treatment, and the collateral circulation became quickly established. Patient complained of a tingling sensation in the leg during the application of the fingers, but no actual pain was felt, except at the time the hands were changed. Oxide of zinc powder was dusted on the skin over Scarpa's space during the treatment, to prevent abrasion of the skin, and it answered the end effectually. In both legs the posterior tibial artery was felt beating immediately before the compression was started, but on the solidification of the tumour the artery could not with certainty be felt in either foot. The temperature remained alike in both legs, and was at first only slightly below the normal standard. As before stated, pain was complained of only on the gentlemen changing places, but towards night he ceased to notice the change, and was observed to become drowsy.

The order given was to "Stop the pulsation in the aneurism completels, and keep it so," and this order was literally carried out. The gentlemen who kindly volunteered their aid in this case, found that from fifteen to twenty minutes was as long a period as any one of them could effectually compress the artery. Two at least were always at the bedside, and while one pressed the artery, his companion kept his open hand over the sac. In both cases the knee was slightly flexed, and resting on a pillow, and each compressor stood during his turn. From the practice obtained in the right limb, the students found that they were able to manage the ressel with the more ease in the left thigh.

Jan. 23rd, 1877.- Since date of cure both knees have been kept bent, as a precautionary measure, but to-day the bandages were removed. The tumour in the right ham gives the feel of a firm fibrous tumour, about the size of a walnut; that in the left being a little larger and scarcely so dense. The posterior tibial arteries can barely be felt pulsating, yet the temperature is normal and alike in both feet. A small vessel, much enlarged, passes over the outer aspect of each tumour, and one also over the front of the patella.

Feb. 23rd.-Dismissed, and warned not to take long walks in the meantime.

I have tied the femoral artery five times for popliteal aneurism, with one death, in which case, while the patient lay in bed, during the healing process, an aneurism formed in the opposite ham; gangrene of both feet ensued, and the man sank. In another case I effected a cure in three days by flexing the leg firmly on the thigh and keeping it in that position by careful bandaging.

So far as is known to me, this is the only case on record in which two aneurisms in the same individual have been cured in the short period of twenty-one hours.

Glasgow.

Donations to Medical Charities. - Major Moriarty, of Plymouth, has given $£ 1000$ to University College Hospital, $\& 100$ to the Royal Medical Benevolent College, and $\$ 100$ to St. John's Maternity Home. Joseph Gurney Barclay has given $\$ 500$ to the building fund of the North-Eastern Hospital for Children, Hackney-road H. S. C. and the Grocers' Company have each given $\$ 100$ to the extension fund of the Charing-cross Hospital. The Corporation of London have given 300 guineas to the fund for rebuilding the Metropolitan Free Hospital. The Gold6miths' and Mercers' Companies have each given $\$ 100$ to the reparation fund of the Westminster Hospital.
SOME REMARKS

ON THE DISCOVERY OF THE AN ESTHETIC EFFECTS OF CHLOROFORM, AND ITS FIRST EXHIBITION IN ENGLAND.

Bт M. C. FURNELL, M.D., F.R.C.S., SURGEOW-MAJOR H.M.'S INDTAN SBRVICE, PRINCIPAL OF THH MADRAS MRDICAL COLLEGE, BTC.

I HAVE no desire whatever in the following remarks to attempt to snatch a single laurel from the wreath of fame which encircles the brow of Sir James Simpson. To his other merits, as one of the most able and famous medical men of his time, Sir James Simpson has had added the reputation of having first discovered, and then introduced to the world, the use of chloroform as an anæsthetic. That he first intro. duced it in Edinburgh, and by his example, and owing to his eminent position, made the use of chloroform quickly and widely popular throughout the civilised world, is a matter which admits of, and happily needs, no denial; but I think I shall be able to show in the following remarks that five or six months before Six James Simpson used this beneficent agent, it had been first taken, and then brought to tha notice of two eminent hospital surgeons of London by the writer of these lines, then a young student just commencing the study of medicine.

The subject has not only been noticed by Dr. Edward $S_{*}$. Dunster in his paper "The History of Anæsthesia," but has lately formed a topic of discussion in one of the leading daily papers of the presidency in which $I$ am serving, and the statements there made by a correspondent signing himself "X. Y.Z." led me to make some inquiries in the matter full of interest to myself, and not without interest, I hope, to the medical profession.

I will first relate, as concisely as I can, my connexion. with this discovery of the anæsthetic properties of chloroform, how it lay buried so many years, and how the subject was again resuscitated.

It was in the year 1846 that Dr. Morton, of Boston, made known his grand discovery of anæsthesia by sulphurio ether, one of the most astounding revolutions in medi. cine. Before this time, to use the words of Velpean, " a cutting instrument and pain in operative surgery wero inseparably connected in the minds of pationts, and there seemed no appeal from this apparently necessary associa tion." Men who can remember the operating theatre of a large hospital before Dr. Morton's discovery are gradually passing away; they are every day becoming fewer. I can well remember even now one of the first operations $I$ saw under the old régime. It was on a girl who had in childhood been desperately burnt on the neck and shoulders by falling into a fire. The cicatrix had gradually contracted, so as to draw the unfortunate creature's head down on her breast and her lower lip away from the mouth, exposing the lower row of teeth and allowing the saliva to dribble continually from her mouth. She was a repulsive spectacle, and had gladly consented to Mr. Skey's suggestion of an operation which, by transplanting a piece of skin from her arm and dissecting up the cicatrix, appeared to afford some chance of mitigating her unfortunate appearance. The patient was tied to the operating-table, as was customary in those days, but before many minutes of the operation had elapsed, her cries and entreaties to be untied and allowed to remain as she was were the most frightful that can be imagined. As the operation, which was necessarily a lengthy and slow one, proceeded, her cries became more terrible first one and then another student fainted, and ultimately all but a determined few had left the theatre unable to stand the distressing scene. I have since that time assisted, as the French say, at some painful sights. I have seen a strong man flogged for gross insubordination in the field, but his sufferings were light as air compared with the agonies this poor girl must have undergone. These terrible scenes in the operating theatre of a hospital were of weekly, almost daily, occurrence, when Dr. Morton's merciful discorerg. 